\title{
Application of the ICF to referral delay in total joint arthroplasty
}

\author{
Diane Dixon, ${ }^{1}$ Beth Pollard, ${ }^{2}$ David Rowley, ${ }^{3}$ Marie Johnson ${ }^{2}$
}

'Department of Psychology, University of Strathclyde, Glasgow, UK ${ }^{2}$ Institute of Applied Health Sciences, University of Aberdeen, Aberdeen, UK ${ }^{3}$ Department of Orthopaedic and Trauma Surgery, Ninewells Hospital, Dundee, UK

\section{Correspondence to} Dr Diane Dixon Department of Psychology, University of Strathclyde, 40 George Street, Glasgow G1 10E UK; diane. dixon@strath.ac.uk

Accepted 22 October 2008 Published Online First 27 June 2010

\begin{abstract}
Background The factors that affect referral for total joint arthroplasty (TJA) have been widely studied. Implicit in this work is the assumption that patient health status should determine priority for surgery. However, specification of patient health status lacks a strong theoretical framework. This study employs the WHO model of health outcomes, the International Classification of Functioning, Disability and Health (ICF), to examine patient health factors in the referral process for TJA. Methods Within 8 weeks prior to TJA, 260 patients electing for primary TJA completed a questionnaire which measured the ICF (impairment, activity limitations and participation restrictions) and four types of delay in their journey from initial consultation with their primary care physician to surgery.
\end{abstract}

Results Impairment did not affect any stage of the referral process. In contrast, patients who had experienced a delay of 26 weeks or less between referral to a surgeon and being placed on the waiting list for surgery reported greater activity limitations and participation restrictions than patients who had waited more than 26 weeks. Further, patients who reported having wanted surgery for more than 52 weeks reported greater participation restrictions than patients who had wanted surgery for less than 52 weeks.

Conclusions The ICF identifies three health outcomes, two of which (activity limitations and participation restrictions) are related to delay in the referral process for TJA. The ICF is a useful theoretical framework for the study of factors that influence prioritisation for surgery. The level of functional and social disability appears to inform prioritisation for TJA by consultant orthopaedic surgeons.

\section{INTRODUCTION}

The UK and other governments publish guidelines and targets for maximum waiting times for TJA; consequently, referral for TJA has been subject to much scrutiny-for example, checklist-based point systems that prioritise surgery according to scores for pain, physical disability, joint damage and social participation have been developed. ${ }^{1-3}$ Qualitative work with patients has shown some agreement with the checklist criteria, in that patients believe those with severe pain or disability should be prioritised. ${ }^{4}$ Implicit in this type of work is the assumption that patient health status should determine prioritisation, and hence delay. However, the specification of patient health status lacks a strong theoretical framework, and while it is important to identify and understand the factors that affect delay at each stage in the referral process, it is equally important to employ a valid theoretical framework to structure that understanding. If one considers the referral process to be an important potential contributor to patient outcome ${ }^{56}$ then health-outcome models may be able to provide such a theoretical framework.

This study employs the WHO model of health outcomes, namely the International Classification of Functioning, Disability and Health (ICF), ${ }^{7}$ to examine patient health factors in the referral process for orthopaedic surgery. The ICF identifies three main health outcomes, namely, impairment (I), activity limitations (A) and participation restrictions (P) (see figure 1). To date, the ICF has primarily been used to examine the consequences of a given health condition; however, it may also be able to inform our understanding of patient factors that influence or guide the referral process. Indeed, the ICF was designed as a framework to aid the definition, measurement and policy formulations for health and disability ${ }^{7}$ and should, therefore, be a suitable tool for examining the factors that influence delay. Such an analysis is possible because health outcome measures used in orthopaedics have recently been classified according to whether they measure the impairment, activity limitations or participation restriction components of the ICF, or a mixture thereof. ${ }^{8}$ Consequently, standard orthopaedic outcome measures can be used to measure the ICF.

Four categories of delay can be identified within the patient's journey to TJA following consultation with their primary care physician (general practitioner, GP), namely, the time between first seeing the GP and being referred to a Orthopaedic Consultant (GP delay), the time between referral and being placed on the waiting list for TJA (surgeon delay), the time spent on the waiting list (waiting list delay) and the time for which a patient wanted surgery (patient perception). This study examines the relationship between the four categories of delay and the level of impairment, activity limitations and participation restrictions reported by patients awaiting primary joint replacement surgery.

\section{METHOD \\ Design}

A geographical cohort of participants from Ninewells Hospital, Dundee was examined. Prior to surgery, each patient received a postal questionnaire, which assessed the four categories of delay and ICF health components.

\section{Participants}

Three hundred and fifty patients assessed within 8 weeks of primary hip or knee joint replacement surgery returned postal questionnaires (representing $43 \%$ of the sample $(n=814)$ to which questionnaires 


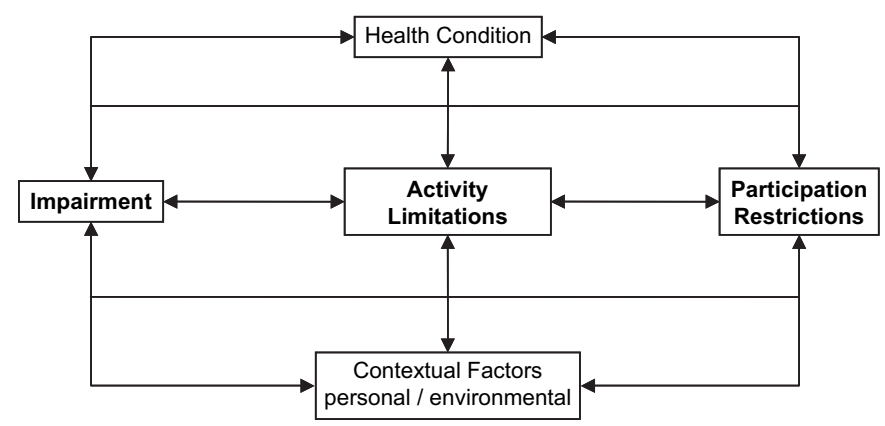

Figure 1 International Classification of Functioning Disability and Health (ICF).

were posted). Of the 350 returned questionnaires, 260 passed the test for correct completion (correct completion rate $74 \%$ ). Questionnaires were judged to have been completed correctly if the self-reported date for surgery matched that on the patient's medical record. (A match between the self-reported date of surgery and the actual date of surgery was used to identify patients who might be less likely to exhibit recall error.) The mean age of participants was $67.9(\mathrm{SD}=9.9) ; 49.6 \%$ of the sample were male and $57 \%$ of participants were having hip replacement.

\section{Measures}

Delay categories

Measures of each delay category were based on patient selfreport.

1. GP delay: time between first seeing a GP and being referred to a consultant;

2. surgeon delay: time between referral and being placed on the waiting list;

3. waiting list delay: time on the waiting list;

4. patient perception: how long each participant had wanted surgery.

\section{ICF components}

All ICF components were measured by items previously identified as being measures of I, A or P. ${ }^{8}$ Current levels of each component were measured as follows:

1. impairment: pain subscale from WOMAC (WOMAC-Pain); a higher score indicated greater impairment;

2. activity limitation: physical function subscale from WOMAC (WOMAC-Physical); a higher score indicated greater activity limitation;

3. participation restriction: social subscale from the RAND SF-36 (SF36-Social) and the social subscale from the WHOQOL (WHOQOL-Social); for both measures a higher score indicated less participation restriction.

\section{Analysis}

The 2005/2007 UK government guidelines for referral to seeing a consultant and waiting list delay were used to inform how the sample was split into the two groups to be compared. The following criteria were used: GP delay $\leq 52$ weeks; surgeon delay and waiting list delay $\leq 26$ weeks and $\leq 18$ weeks; patient perception $\leq 52$ weeks. The impairment, activity limitations and participation restriction scores for each group were then compared using ANOVA.

\section{RESULTS}

\section{Drop-out analysis}

There were no differences in age, gender, American Knee Society (score or function) measures, or Harris hip score between those patients who returned a questionnaire (both correctly or incorrectly completed) and those that did not. In addition, there were no differences in age, American Knee Society (score or function) measures or Harris hip score between the 260 patients who completed the questionnaire correctly and the 90 who did not.

\section{Delay data}

The distribution of all four measures of delay showed a positive skew. Nearly one-quarter of participants had no GP delay. Sixtythree per cent of participants had a GP delay of 1 year or less. Nineteen per cent of participants had no surgeon delay. Fifty per cent of participants had 26 weeks' or less surgeon delay, with $39 \%$ of participants having less than 18 weeks' surgeon delay. Fifty-four per cent of participants had 26 weeks' or less waiting list delay, with $20 \%$ of participants having less than 18 weeks' waiting list delay. Sixty-two per cent of participants had wanted surgery for 1 year or less.

\section{Delay group differences in ICF components}

The mean scores on each ICF component for each delay group are shown in table 1. The impairment scores did not differ significantly between delay groups for any of the four delay categories.

In contrast, there were some significant group differences in the activity limitations and participation restriction scores. Individuals who had experienced a surgeon delay of 26 weeks or less reported greater activity limitations than individuals who had experienced a surgeon delay of more than 26 weeks $\left(\mathrm{F}_{1,224}=4.6, \mathrm{p}=0.033\right)$. While individuals who had experienced surgeon delay of 18 weeks or less reported greater activity limitations than those who had experienced a surgeon delay of more than 18 weeks, the difference between the groups was no longer significant $\left(\mathrm{F}_{1,224}=3.0, \mathrm{p}=0.08\right)$.

When measured by the RAND SF-36 Social scale, differences in participation restrictions were observed in surgeon delay. Individuals who experienced a surgeon delay of 26 weeks or less reported greater participation restrictions that those who had experienced a surgeon delay of more than 26 weeks $\left(F_{1,224}=5.4\right.$, $\mathrm{p}=0.021)$. This difference between the surgeon delay groups was maintained when the 18 weeks or less criterion was used to generate the two groups $\left(\mathrm{F}_{1,224}=4.7, \mathrm{p}=0.031\right)$. When measured by the WHOQoL-Social scale, individuals who reported having wanted surgery for more than 52 weeks reported greater

Table 1 Mean scores (SD) on each International Classification of Functioning Disability and Health component for each delay group

\begin{tabular}{|c|c|c|c|c|c|}
\hline \multirow[b]{2}{*}{ Delay category } & \multirow{2}{*}{$\begin{array}{l}\text { No of weeks' } \\
\text { delay for each } \\
\text { group }\end{array}$} & \multirow{2}{*}{$\begin{array}{l}\text { Impairment* } \\
\text { WOMAC } \\
\text { pain }\end{array}$} & \multirow{2}{*}{$\begin{array}{l}\text { Activity } \\
\text { limitations* } \\
\text { WOMAC } \\
\text { physical }\end{array}$} & \multicolumn{2}{|c|}{$\begin{array}{l}\text { Participation } \\
\text { restrictions } \uparrow\end{array}$} \\
\hline & & & & $\begin{array}{l}\text { SF-36 } \\
\text { social }\end{array}$ & $\begin{array}{l}\text { WHOQoL } \\
\text { social }\end{array}$ \\
\hline \multirow[t]{2}{*}{ GP consultant } & $\leq 52$ & $16.7(3.2)$ & $55.6(11.4)$ & $6.7(2.2)$ & $11.2(2.3)$ \\
\hline & $>52$ & $16.9(3.4)$ & $55.3(12.0)$ & $6.8(2.5)$ & $11.3(2.1)$ \\
\hline \multirow[t]{4}{*}{ Referral list } & $\leq 18$ & $16.7(3.3)$ & $57.1(11.2)$ & $6.4(2.3)^{\mathrm{a}}$ & $11.1(2.0)$ \\
\hline & $>18$ & $16.8(3.3)$ & $54.4(11.8)$ & $7.1(2.3)^{\mathrm{a}}$ & $11.3(2.2)$ \\
\hline & $\leq 26$ & $16.8(3.2)$ & $57.1(11.1)^{\mathrm{b}}$ & $6.5(2.3)^{c}$ & $11.2(1.9)$ \\
\hline & $>26$ & $16.7(3.4)$ & $53.8(11.9)^{\mathrm{b}}$ & $7.1(2.3)^{\mathrm{c}}$ & $11.2(2.2)$ \\
\hline \multirow[t]{2}{*}{ Waiting list } & $\leq 26$ & $16.7(3.3)$ & $54.4(12.1)$ & $6.9(2.3)$ & $11.3(2.3)$ \\
\hline & $>26$ & $16.8(3.3)$ & $56.7(10.9)$ & $6.8(2.4)$ & $11.1(2.1)$ \\
\hline \multirow[t]{2}{*}{ Wanted surgery } & $\leq 52$ & $16.5(3.3)$ & $54.9(11.6)$ & $6.9(2.2)$ & $11.5(2.1)^{d}$ \\
\hline & $>52$ & $17.3(3.4)$ & $56.3(11.6)$ & $6.5(2.5)$ & $10.9(2.3)^{d}$ \\
\hline
\end{tabular}

*Higher impairment and higher activity limitation scores indicate worse impairment and greater activity limitations.

†Higher participation restriction scores indicate reduced participation restrictions. Scores labelled with the same superscript letter were significantly different $(p \leq 0.05)$. 
participation restrictions than individuals who had wanted surgery for 52 weeks or less $\left(\mathrm{F}_{1,224}=3.9, \mathrm{p}=0.031\right)$.

\section{DISCUSSION}

The current study suggests that primary care physicians do not refer patients for consultation by an orthopaedic surgeon based on their level of impairment, activity limitations or participation restrictions. In contrast, orthopaedic consultants do appear to employ activity limitations and/or participation restrictions to prioritise patients for surgery. Patients who report higher activity limitations and greater participation restrictions received an earlier referral for TJA. However, once a patient was on the waiting list, neither activity limitations nor participation restrictions affected the length of time on the waiting list. These data are consistent with a previous Canadian study that reported some evidence for clinical prioritisation on the basis of activity limitations; patients who waited less than 6 months for hip replacement had higher scores on the WOMAC-physical scale and performed worse on a 6 min walk test than those waiting less than 6 months. ${ }^{5}$

That said, orthopaedic consultants did not use impairment, measured in this study as pain, to prioritise patients for TJA. It is possible that the level of pain experienced by this group of patients is sufficiently homogeneous to preclude the use of pain as a means to discriminate patients for higher prioritisation for TJA. In contrast, in the Canadian study, worse pain and greater joint stiffness were associated with reduced waiting times for hip-replacement surgery. ${ }^{5}$ However, other studies conducted in the UK and Canada failed to show any evidence of clinical equity in the prioritisation for TJA. 910

There was some concordance between consultants and patients, in that patients who had wanted surgery for more than a year reported greater participation restrictions but not higher impairment or activity limitations. These data are consistent with previous evidence which suggests that patients experience a decline in mobility and health-related quality of life if they are required to wait longer than 6 months for surgery. ${ }^{5}$

Quite clearly, the criteria being used by the surgeons to determine the necessity of requirement for a joint replacement reflect the indications being based on clear clinical criteria related to pain and function. Unfortunately, under the conditions in which surgeons form their waiting lists, the principal determinant of waiting time is strictly related to the order on which they are wait-listed, with an overall global limit of, on average, 18 weeks, during which all patients should now be offered surgery. This is clearly in advance of the conditions at the time this study was carried out. Nevertheless, the inability to control waiting time by clinical priority is an ongoing source of frustrations clearly supported by the impressions that patients have. It therefore behoves us to take great care to try to design studies that would demonstrate the benefit of a score-related prioritisation, provided there is a safety net that ensures lower-priority patients would ultimately get to the point of being offered surgery.

The other issue that is raised by the study is the discrepancy between indications for referral to the surgeon and the surgeons' indications for wait listing for surgery. There is clearly a communication issue between the primary carers' understanding of the indication for joint replacement and that of the surgeons. An improvement in communication at this level might considerably improve the efficiency of the patient journey and ultimately foreshorten it for those in maximum need.
There are some limitations to this study. First, the delay data are based on self-report, and although only those patients who were able to report the date of their surgery correctly were included in the analyses, recall bias or error cannot be ruled out, and this could have affected the results. Future studies would benefit from a prospective design that recruits participants from primary care and tracks their journey through the referral and waiting-list system using both self-report and objective measures. Second, the study examined multiple types of delay, and as a consequence the Type I error rate may have been inflated. We have reported the actual $p$ values for those comparisons significant at the 0.05 level to enable judgement of this issue and to facilitate comparison with any future studies. Finally, it would be of interest to know how the differences in activity limitations and participation restriction scores observed in the current study relate to the minimal clinically important difference (MCID), that is, the minimal difference detectable by patients, for measures such as the WOMAC and SF-36. Studies in this area have concentrated on MCID values after an intervention (be that joint replacement or rehabilitation), and it is not clear that MCID data from these studies are applicable to differences in activity limitations and participation restrictions perceptible to patients prior to surgical intervention. ${ }^{11}{ }^{12} \mathrm{An}$ examination of minimal difference, in each of the ICF outcomes, perceptible to patients living with chronic conditions such as $\mathrm{OA}$ would be useful.

Acknowledgements The authors would like to thank all the participants in the study and the staff at Ninewells, all of whom contributed much time and effort to this study.

Funding The Medical Research Council-Health Services Research Collaboration funded this study.

Competing interests None.

Patient consent Obtained.

Ethics approval Ethics approval was provided by the Tayside NHS Ethics Committee

Provenance and peer review Not commissioned; externally peer reviewed.

\section{REFERENCES}

1. Conner-Spady B, Estey A, Arnett G, et al. Prioritization of patients on waiting lists for hip and knee replacement: validation of a priority criteria tool. Int $J$ Technol Assess Health Care 2004;20:509-15.

2. Hadorn DC, Holmes AC. The New Zealand priority criteria project. Part 1: overview. BMJ 1997;314:131-4.

3. Toye F, Barlow J, Wright C, et al. A validation study of the New Zealand score for hip and knee surgery. Clin Orthop Relat Res 2007;464:190-5.

4. Woolhead GM, Donovan JL, Chard JA, et al. Who should have priority for a knee joint replacement? Rheumatology 2002;41:390-4.

5. Mahon JL, Bourne RB, Rorabeck CH, et al. Health-related quality of life and mobility of patients awaiting elective total hip arthroplasty: a prospective study. Can Med Assoc J 2002;167:1115-21.

6. Fortin PR, Clarke AE, Joseph $\mathrm{L}$, et al. Outcomes of total hip and knee replacement-preoperative functional status predicts outcomes at six months after surgery. Arthritis Rheum 1999;42:1722-8.

7. World Health Organization. International classification of functioning, disability and health: ICF. Geneva: World Health Organization, 2001.

8. Pollard B, Johnston M, Dieppe P. What do osteoarthritis heath outcome instruments measure? Impairment, activity limitation or participation restriction? J Rheumatol 2006;33:757-63.

9. Fitzpatrick R, Norquist JM, Reeves BC, et al. Equity and need when waiting for total hip replacement surgery. J Eval Clin Pract 2004;10:3-9.

10. Kelly K, Voaklander D, Johnston W, et al. Equity in waiting times for major joint arthroplasty. Can J Surg 2002:45:269-76.

11. Angst F, Aeschlimann A, Stucki G. Smallest detectable and minimal clinically important differences of rehabilitation intervention with their implications for required sample sizes using Womac and Sf-36 quality of life measurement instruments in patients with osteoarthritis of the lower extremities. Arthritis Rheum 2001:45:384-91.

12. Escobar A, Quintana JM, Bilbao A, et al. Responsiveness and clinically important differences for the Womac and SF-36 after total knee replacement. Osteoarthr Cartil 2007; 15:273-80 